\title{
The art of Latina and Latino elderhood: A note from the editor
}

\section{Lourdes Torres $^{1}$}

Published online: 16 November 2021

(c) The Author(s), under exclusive licence to Springer Nature Limited 2021

It is widely recognized that Latinos are a sizable and diverse population and that we are a young demographic. The median age of non-Hispanic white Americans is 58, whereas for Latinos it is $30 .{ }^{1}$ Perhaps this partially explains the dearth of attention afforded to the topic of aging Latinos by academic scholarship and the mainstream media. This special issue compellingly alerts us to the reality that there is a growing, aging Latino population about which we know very little and that deserves our attention. I am grateful to Katynka Martínez and Mérida Rúa for curating "The Art of Latina and Latino Elderhood," since this special issue responds to this significant gap in our knowledge with an exciting set of academic articles and creative contributions that challenges not only our assumptions about Latinos and aging but also our thinking on the types of contributions we include in our journal pages. Katynka and Mérida make the case that the story of Latino elderhood is best conveyed through a truly multidisciplinary and interdisciplinary approach, bringing together public policy, humanistic social sciences, and artistic interventions. So, for the first time, Latino Studies is pleased to feature a novel in progress, a photo essay/dialógo, an artist's monologue, and a dialogue among actors alongside more traditional academic articles. I think you will agree that this issue before you beautifully conveys why the subject of Latinos and aging should concern all of us, and that it will powerfully spur other researchers and artists to take up the invitation to continue to share new evocative stories about the pleasures, difficulties, and complexities of Latinx later life. Enjoy!

\footnotetext{
Lourdes Torres

ltorres@depaul.edu

1 DePaul University, Chicago, IL, USA
}

1 https://www.pewresearch.org/fact-tank/2019/07/30/most-common-age-among-us-racial-ethnic-groups/. 
Publisher's Note Springer Nature remains neutral with regard to jurisdictional claims in published maps and institutional affiliations. 